\title{
MORCEGOS (MAMMALIA: CHIROPTERA) NA PERCEPÇÃO DE ALUNOS DE ÁREA RURAL E URBANA NO MUNICÍPIO DE TEUTÔNIA, VALE DO TAQUARI (RS)
}

Camila Griebeler ${ }^{1}$

Liana Johann ${ }^{2}$

Resumo: Rodeados de crenças e mitos de pessoas sem o conhecimento de sua morfologia, ciclo de vida, hábitos alimentares e nichos ecológicos, os morcegos são vistos como ratos velhos com asas, animais que não possuem visão e vampiros que se alimentam de sangue. Este trabalho teve por objetivo avaliar o conhecimento de alunos do ensino fundamental de escolas públicas de zona rural e urbana sobre a fauna de morcegos, além de verificar a importância da Educação Ambiental. A maioria dos alunos, das duas áreas, nunca aprendeu sobre morcegos, o que justifica seus mitos e crenças relacionados aos morcegos. É perceptível que grande parte dos alunos possuía medo dos morcegos por não conhecer sua importância no meio ambiente, apresentando informações falsas. As atividades de Educação Ambiental são fundamentais pois, em ambas as áreas, desmitificaram e acabaram com grande parte do preconceito gerado sobre esta ordem animal.

Palavras-chave: Morcegos; Cidades; Área agrícola; Ensino Fundamental; Educação Ambiental.

1 Universidade do Vale do Taquari - Univates. E-mail: camilaa_griebeler@hotmail.com

2 Universidade do Vale do Taquari - Univates. E-mail: liana@univates.br

Revbea, São Paulo, V. 16, № 2: 316-330, 2021. 
Abstract: Surrounded by the beliefs and myths of people without the knowledge of their morphology, life cycle, eating habits and ecological niches, bats are seen as old rats with wings, animals that lack vision, and blood-feeding vampires. The objective of this study was to evaluate the knowledge of elementary school students in rural and urban public schools on the fauna of bats, as well as to verify the importance of environmental education. Most students in both areas have never learned about bats, which justifies their myths and beliefs related to bats. It is noticeable that most of the students were afraid of bats because they did not know their importance in the environment, presenting false information. Environmental education activities are fundamental because, in both areas, they demystified and ended much of the prejudice generated by this animal order.

Keywords: Bats; Cities; Agricultural Area; Basic Education; Environmental Education.

\section{Introdução}

Pertencentes a ordem Chiroptera, palavra derivada do grego que significa mão (cheir) e asa (ptero), os morcegos são os únicos mamíferos capazes de voar (REIS et al. 2013). Suas asas são adaptadas, contendo um prolongamento de pele fino e bastante irrigado denominado patágio. Os dedos dos membros anteriores possuem um alongamento se comparados com o restante dos mamíferos. Outra adaptação desenvolvida, foi a ecolocalização, que juntamente com a visão, orienta-o na escuridão da noite. Para localizar alimentação e desviar dos obstáculos os morcegos emitem ondas de alta frequência enquanto voam. Ao encontrar-se com algum objeto ou ser vivo, estas ondas retornam e são receptadas pelo trago, localizado na entrada do pavilhão auricular, e pela folha nasal (uma pequena estrutura do rosto com formato de folha, presente em algumas espécies) (NOVAES, 2008).

Segundo Reis et al. (2007), o grupo dos morcegos possui uma grande diversidade em relação aos hábitos alimentares. A maioria das espécies é insetívora, tendo como principal nicho ecológico o controle populacional de invertebrados e pragas agrícolas. (PACHECO et al, 2010). Conforme Bredt; Pedro (2012) os frugívoros e os polinívoros/nectarívoros são respectivamente dispersores e polinizadores de mais de 500 espécies de plantas, contribuindo para recomposição de áreas degradadas. Os piscívoros, carnívoros e os hematófagos realizam o controle populacional de vertebrados (MARQUES; PACHECO, 2008). Segundo Uieda (2008), na saliva do morcego hematófago são encontradas substâncias anticoagulantes, as quais são estudadas pela farmacologia para uso em tratamentos do sistema circulatório.

Sendo o segundo maior grupo de mamíferos, os morcegos possuem mais de 1300 espécies distribuídas em várias partes do mundo (VOIGHT; KINGSTON, 2016). No Brasil, segundo Nogueira et al. (2014), existem um total de 178 espécies, 68 gêneros e nove famílias. A fauna de Chiroptera do Rio Grande do Sul é constituída por 40 espécies, e quatro famílias: Molossidae,

Revista brasileira educação ambiental 
Phyllostomidae, Vespertilionidae e Noctilionidae, apresentando a menor diversidade da região sul do Brasil (PASSOS et al. 2010). Segundo estudos de Kasper et al. (2007), Pacheco et al. (2008), Reis et al. (2013), no Vale do Taquari, o qual a cidade de estudo deste trabalho está inserida, foram observadas em torno de 20 espécies de morcegos pertencentes às quatro famílias nas áreas urbanas e rurais. Noctilio leporinus (Linnaeus) é uma espécie que apresenta hábito alimentar piscívoro, Chrotopterus auritus (Peters) é carnívoro, Desmodus rotundus (E. Geoffroy) é hematófago, Artibeus lituratus (Olfers), Artibeus fimbriatus Gray, Sturnira lilium (E. Geoffroy) são frigívoros, Glossophaga commissarisi (Gardner) especializado no consumo de pólen e néctar e o restante das espécies são insetívoras, tais como: Molossus molossus (Pallas), Molossus rufus E. Geoffroy, Tadarida brasiliensis (I. Geoffroy).

Ao mencionar a palavra "morcego", grande parte da população associa com algo maléfico e perigoso para o ser humano, já que este animal tem hábitos noturnos e é pouco conhecido pela sociedade (BREDT; SILVA, 1998). Rodeados de crenças e mitos de pessoas sem o conhecimento de sua morfologia, ciclo de vida, hábitos alimentares e nichos ecológicos, são vistos como ratos velhos com asas, animais que não possuem visão e vampiros que se alimentam de sangue humano. Essas informações geralmente são trazidas pelas gerações antecedentes e pela ficção cinematográfica. Muitas pessoas desconhecem os morcegos, pela falta de contato direto, ou por falta de conhecimento básico, englobando-o no grupo de animais mais parecidos com as características observadas, provocando uma errada classificação, muitas vezes generalizada de suspeita (DRUMMOND, 2008).

Devido aos mitos, crenças e superstições, muitas populações de morcegos são exterminadas pelos seres humanos, causando grande impacto no ambiente ao qual estavam inseridas (SILVA, 2014). Reis (2003) retrata que os desmatamentos e a fragmentação florestal também ameaçam a existência dos morcegos, já que destroem seus abrigos. Conforme Bernard et al. (2012), a redução ou alteração de leis ambientais, aumenta as ameaças aos morcegos, pois diminui a proteção das cavernas naturais, das áreas de proteção permanentes (APPs) e das normas e cuidados de exterminação de pragas. Além disso, o funcionamento das hidrelétricas e das torres eólicas podem ocasionar mortes ou perda de seus refúgios. Telhados, foros e porões, são exemplos de locais de abrigo de muitas espécies de morcegos, ocasionando um desconforto nas pessoas residentes destes locais, já que há barulhos e presença de fezes. Não é incomum as pessoas vedarem os telhados e juntas de dilatação sem realizar o devido manejo dos indivíduos, ocasionando a morte dos animais, e consequentemente um cheiro desagradável, devido ao estado de putrefação dos mesmos (PACHECO et al., 2010).

Segundo Mansolo (2012), o ser humano está cada vez mais afastado do natural, esquecendo a função de cada ser vivo e de sua importância no meio em que está inserido. Considera a presença de alguns animais silvestres como 
ameaçadora, classificando-os como "inimigos naturais", esquecendo como é conviver de forma harmônica com o meio ambiente. A civilização está mais próxima das máquinas, desconectando-se da essência natural da vida. $A$ Educação Ambiental tem como função reconectar o ser humano ao meio natural, mostrar que ele é responsável pela manutenção da vida, e que suas atitudes podem trazer benefícios ou malefícios. Ou seja, tudo está relacionado, como se fosse uma grande teia, cada ação repercute em resultados, sejam eles bons ou ruins.

Influenciados pelas mídias de que os morcegos são criaturas sinistras e malignas, as crianças, jovens e adultos, não conseguem ver estes animais como algo positivo. Por isso, a Educação Ambiental é fundamental, pois mostra para estas pessoas que os morcegos têm um importante papel ecológico na polinização, dispersão de sementes e no controle de populações de invertebrados e vertebrados (PALEARI, 2008).

Este trabalho teve por objetivo avaliar o conhecimento dos alunos de escolas públicas de zona rural e urbana sobre a fauna de morcegos. Além disso, verificou-se a importância da Educação Ambiental como forma de sensibilização e conscientização sobre a importância desse grupo animal.

\section{Procedimentos metodológicos}

O presente trabalho foi desenvolvido no munício de Teutônia - RS, cidade de imigração alemã, localizada no Vale do Taquari, na região central do Estado, a $110 \mathrm{~km}$ de Porto Alegre e com área de $178,460 \mathrm{~km}^{2}$. O município destaca-se na produção agropecuária, tendo como principais enfoques a bovinocultura leiteira, avicultura e suinocultura. Na área urbana destaca-se o setor industrial, tendo um alto índice de munícipes empregados em indústrias alimentícias e calçadistas (PREFEITURA MUNICIPAL DE TEUTÔNIA, 2019).

Em Teutônia existem 18 escolas que oferecem o Ensino Fundamental, públicas e privadas, entre elas oito são de área rural e dez de área urbana. Para este trabalho foram selecionadas duas escolas municipais, uma de área urbana e outra de área rural. A escola de área rural possui classe multisseriada de educação infantil ao 9o ano do ensino fundamental, com o total de 56 alunos. É uma escola de 120 anos. Possui 3 salas de aula onde ocorre 0 ensino formal, além de atividades extraclasse, oficinas e turno inverso. É uma escola com amplo espaço externo, constituído de área verde, pátio, horta, jardim, relógio de chás, que além de ser espaço usufruído pela comunidade escolar, recebe visitas de outras escolas e pessoas que apreciam o espaço. Outro ponto importante, a ressaltar, é a existência da Cooperativa Escolar, que há 21 anos, tem como principal objetivo desenvolver nos educandos o espírito cooperativista.

A escola de área urbana possui 29 anos, sendo composta por aproximadamente 600 alunos de ensino infantil e fundamental, nos turnos da

manhã e tarde. Contém 14 salas de aula, onde são realizadas as aulas do 
ensino regular, turno integral, além de salas de orientação, Atendimento Educacional Especializado (AEE), Laboratório de Aprendizagem (LA), biblioteca e informática. Possui pouco espaço físico externo, sendo que não há pátio para realizar o recreio escolar. A escola também possui uma Cooperativa Escolar, que há 3 anos está envolvendo os alunos em suas atividades e ações.

\section{Coleta de dados - Primeira parte}

O trabalho iniciou-se com a ida até as escolas selecionadas para uma conversa com a direção sobre o projeto, mostrando a carta padrão de apresentação, fornecida pela Universidade do Vale do Taquari - Univates. Após a aprovação das escolas, foi iniciada a primeira parte do estudo, por meio de aplicação de um questionário, em uma turma de $6^{\circ}$ ano (área urbana) e na área rural em uma turma multisseriada, composta por alunos de $6^{\circ}$ e $7^{\circ}$ ano. Os alunos de ambas as escolas, responderam 12 perguntas sobre morcegos, e realizaram um desenho. Os questionários foram aplicados sem qualquer explicação sobre o assunto abordado, pois tinha o objetivo de analisar os conhecimentos prévios e os eventuais mitos e preconceitos sobre o tema.

\section{Coleta de dados - Segunda parte}

A partir das respostas obtidas nos questionários, foi elaborada uma atividade na forma de aula teórica/prática com slides, destacando aspectos da morfologia, hábitos alimentares, mitos e crenças, cuidados, abrigos e forma de vida dos morcegos, juntamente com material zoológico de via seca e líquida de Chiroptera, Rodentia e Apodiformes, retirados do Museu de Ciências Univates. Os indivíduos de roedor e de ave foram usados para mostrar aos alunos as diferenças de aves, ratos e morcegos. Na atividade prática, os alunos também puderam conhecer e observar as diferenças entre cada espécie de morcego, devido ao seu hábito alimentar e suas principais adaptações para o meio em que vive, foi disponibilizado para visualização um indivíduo de cada hábito alimentar, pertencente a região em que os alunos estão inseridos. Os alunos de ambas as escolas desmistificaram o assunto e tiraram dúvidas. Após a aplicação da atividade, os estudantes novamente responderam o mesmo questionário, juntamente com o desenho.

\section{Análise de dados}

As respostas obtidas dos questionários de ambas as escolas foram interpretadas e tabuladas. Posteriormente, foi realizado o cálculo de frequência e percentual das respostas. Os dados obtidos foram comparados entre as duas escolas nos dois momentos de aplicação do questionário, 0 antes e depois em cada escola. As respostas foram agrupadas por similaridade. 


\section{Resultados e discussão}

$\mathrm{Na}$ zona urbana, dos 16 alunos, oito eram de sexo feminino e oito masculino. E na zona rural, de um total de 17 alunos, dez eram de sexo masculino e sete feminino. Os alunos tinham idade de 11 a 16 anos.

Ao perguntar o que são morcegos, os alunos da escola urbana relataram que são: mamíferos $(50 \%)$, ratos com asas $(31,2 \%)$, vampiros $(12,5 \%)$ e aves $(6,3 \%)$. Já na escola de área rural, a maioria dos alunos respondeu que são mamíferos (58,8\%), seguido de aves (17,6\%) e vampiros (17,6\%). Embora grande parte dos alunos conheçam a morfologia dos morcegos, classificando-o como mamífero, muitos ainda acreditam que eles pertencem a classe das aves, que são ratos velhos ou vampiros. Por ser visto muitas vezes só em atividade de voo, durante a noite, as pessoas associam os morcegos com as aves, pois ambos são animais alados que possuem um tamanho relativamente parecido, dependendo a espécie. Já a associação com os ratos ocorre em vários países, inclusive no idioma germânico, onde os morcegos são chamados de fledermaus (rato-voador). Na cultura brasileira, acredita-se que: "ratos velhos viram morcegos" e que "morcegos são parentes de ratos". Normalmente tal associação é feita pois para algumas pessoas os abrigos e morfologia de ambos os animais apresentam semelhanças. Já a associação do morcego com vampiros é ocasionada pela influência da mídia. Por meio de falsas informações jovens e crianças acreditam que os morcegos são algo sobrenatural. (DRUMMOND, 2008; PACHECO, 2008).

Ao se tratar de hábitos alimentares, os alunos, principalmente de área urbana citaram diversos tipos de alimentos. A maioria descreveu mais de um alimento, relatando que os morcegos têm uma alimentação diversificada. $O$ alimento mais citado na área urbana foi "insetos" (23,3\%) (Figura 1). Essa observação é corroborada por Bredt; Silva, (1998) que mencionam que os morcegos insetívoros são encontrados em maior quantidade em áreas urbanas pois há maior disponibilidade de abrigo e alimento, devido a iluminação noturna atrair insetos. Além de ser citado várias espécies de animais como fonte de alimentação dos morcegos, tais como: libélulas, abelhas, lesmas, lagartixas e ratos, também foi mencionado que eles comem cigarro (3,3\%). Segundo Drummond (2008), esta afirmação é uma crença da cultura popular do sul do Brasil, mencionando que os morcegos fumam se colocado um cigarro em sua boca. Na área rural, o alimento mais citado pelos alunos foi "sangue" $(25,9 \%)$, seguido de frutos $(22,2 \%)$ e insetos (22,2\%). De acordo com Uieda (2008), devido a criação de animais em zonas rurais, principalmente os bovinos, o morcego hematófago Desmodus rotundus (E. Geoffroy), é avistado com mais frequência nessas áreas, pela disponibilidade de alimento. Já os morcegos frugívoros tem como principal local de abrigo as árvores frutíferas (MELLO; PASSOS, 2008), as quais são mais abundantes em áreas rurais. 


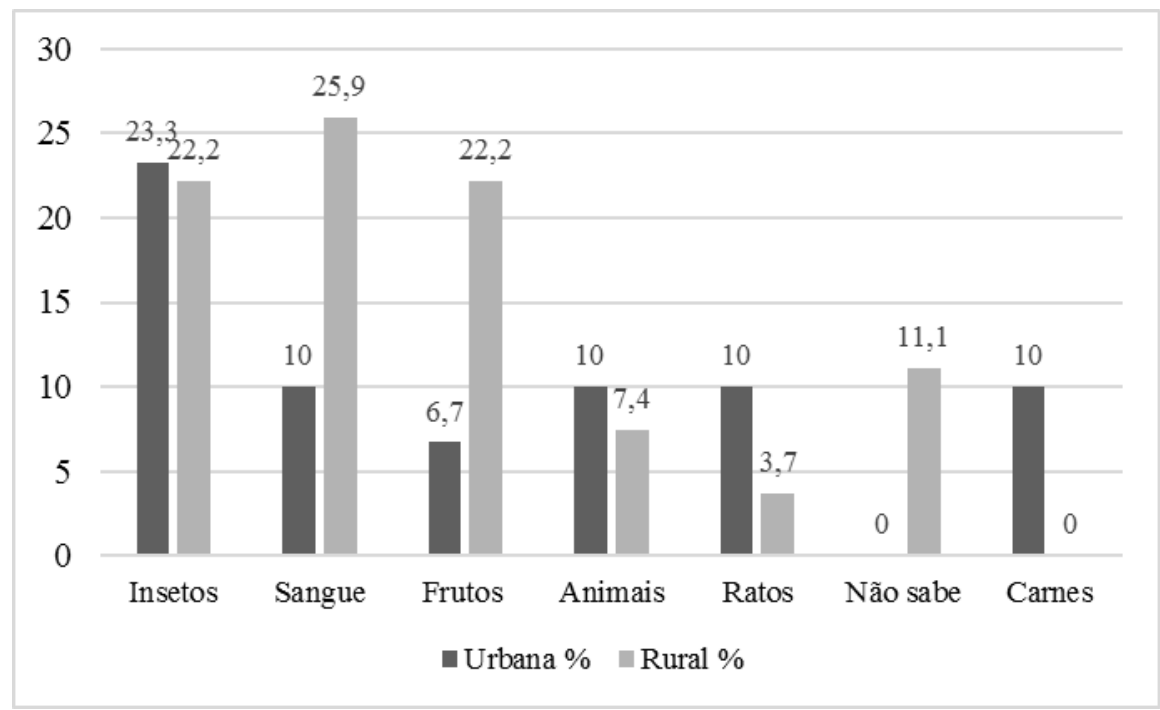

Figura 1: Principais alimentos citados pelos alunos do ensino fundamental de área rural e urbana do município de Teutônia (RS).

Fonte: das autoras.

A maioria dos alunos de área rural relatou que os morcegos são cegos, apresentando uma diferença significativa, em comparação aos resultados da área urbana, onde $68,8 \%$ dos alunos acredita que os morcegos possuem visão (Tabela 1). As pessoas normalmente associam a cegueira com os morcegos, pois eles vivem em ambientes escuros e possuem a ecolocalização como forma de se orientar (DRUMMOND, 2008). Mas os morcegos possuem visão, embora seja pouco desenvolvida, alguns morcegos frugívoros a utilizam bastante (REIS et al. 2007).

Todos os alunos da escola urbana acham que os morcegos podem transmitir doenças, diferente dos alunos de área rural, onde 35,3\% afirmam que os morcegos não podem transmitir doenças. Quando questionados sobre quais doenças os morcegos podem transmitir, os alunos de ambas as áreas não souberam informar. Somente um aluno de área urbana mencionou a raiva associada aos morcegos. E outros dois alunos, um de cada área mencionou vírus e bactérias como doenças que podem ser transmitidas pelos morcegos. Os alunos de área urbana apresentam mais medo dos morcegos do que os alunos da área rural, isso é justificado pois a maioria dos alunos $(37,5 \%)$ mencionou que têm medo pois eles podem transmitir doenças para o ser humano, a outra parte apresenta medo porque os morcegos podem atacar e chupar o sangue das pessoas. Os alunos de área rural apresentam medo dos morcegos pois não os conhecem, pelo fato deste animal ter hábito noturno ou dele poder morder. Entre os alunos que não tem medo quando questionado o porquê, os de área rural responderam que: "não sabem", "os morcegos não atacam pessoas", "nunca viu um morcego", "é só não incomodar", "eles comem frutas" ou "gosto de morcegos". Já a outra escola respondeu que: "não sabe", "eles têm mais medo da gente, que nós deles", "não atacam pessoas", "nunca viu um morcego", "eles são animais", "eles não incomodam". 
Tabela 1: Respostas obtidas a partir da aplicação de um questionário com alunos do ensino fundamental de escolas da zona urbana e rural do município de Teutônia/RS.

\begin{tabular}{lcrcr}
\hline Perguntas sobre morcegos & Escola de Área Urbana & \% & Escola de Área Rural & \% \\
\hline São cegos & Sim & 25 & Sim & 82,4 \\
& Não & 68,8 & Não & 17,6 \\
Transmissores de doenças & Não sabe & 6,2 & Não sabe & 0 \\
& Sim & 100 & Sim & 58,8 \\
& Não & 0 & Não & 35,3 \\
Função ecológica & Não sabe & 0 & Não sabe & 5,9 \\
& Sim & 62,5 & Sim & 76,5 \\
Já viu um morcego & Não & 37,5 & Não & 17,6 \\
& Não sabe & 0 & Não sabe & 5,9 \\
Já aprendeu sobre morcegos & Sim & 62,5 & Sim & 88,2 \\
& Não & 37,5 & Não & 11,8 \\
Possui medo & Sim & 25 & Sim & 29,4 \\
& Não & 75 & Não & 70,6 \\
& Sim & 43,8 & Sim & 23,5 \\
& Não & 56,2 & Não & 76,5 \\
\hline
\end{tabular}

Fonte: das autoras.

Os alunos de ambas as escolas sabem da importância dos morcegos para a natureza, mas ao descrever quais são as funções ecológicas deles, grande parte dos estudantes não sabe (urbana: $36,4 \%$ e rural $35,7 \%$ ). Algumas das funções citadas pelos discentes de área urbana, consistiam em características tais como: "gosta de ambiente escuro", "ele é um animal" e "suga o sangue dos animais", mostrando a falta de conhecimento, sobre o que é de fato uma função. A polinização foi mencionada por uma pequena porcentagem de alunos da área urbana $(9,1 \%)$ e a predação de insetos foi citada em ambas as áreas, (urbana: $9,1 \%$ e rural: $28,6 \%$ ). Somente na área rural foi destacado o morcego como membro da cadeia alimentar $(14,3 \%)$, responsável pela dispersão de sementes $(7,1 \%)$ e de adubar as plantas com suas fezes $(7,1 \%)$. Mostrando que os alunos de área rural têm um maior conhecimento sobre funções ecológicas. Esse conhecimento foi adquirido, provavelmente, no contato com a natureza, devido a escola ter espaço externo para oficinas relacionadas com o meio ambiente, as quais foram mencionadas pela professora e pelos alunos no decorrer da aplicação do estudo.

A visualização de morcegos não é algo incomum, já que a maioria dos alunos, de ambas as escolas, já avistaram este animal. As respostas da área rural, mostram que $60 \%$ dos alunos encontraram morcegos em suas residências, em casas de familiares $(13,3 \%)$ ou na estrada $(13,3 \%)$. Quando questionados sobre o que fizeram, a maioria relatou que somente observou 0 animal (60\%) e $20 \%$ dos alunos relatou que matou ou pediu para alguém matar o morcego avistado. Na área urbana, a maioria dos morcegos visualizados foram em casas de familiares $(27,3 \%)$ e em suas próprias residências $(18,2 \%)$, 
ocorrendo a reação de: somente observar (33,3\%), matar (25\%) e afugentá-lo $(16,7 \%)$. Segundo Zortéa e Aguiar (2008), os morcegos são vistos como algo negativo pela falta de informação da sociedade, ocasionando na morte destes animais quando avistados pelos seres humanos. Embora os alunos tenham relatado que já visualizaram os morcegos, quando questionados se há muitos morcegos em Teutônia, 64,7\% dos estudantes de área rural não sabe se há e os que responderam que sim, a maioria não sabe se é algo bom ou ruim. Os estudantes de área urbana $(37,5 \%)$ responderam que há muitos morcegos em Teutônia, e 31,3\% não sabe se há ou não.

A maioria dos alunos, 70,6\% (área rural) e 75\% (área urbana), nunca aprenderam sobre morcegos, o que justifica seus mitos e crenças relacionados aos morcegos. Uma pequena porcentagem de alunos relatou que já aprendeu sobre morcegos $25 \%$ em área urbana e $29,4 \%$ em área rural, por meio da televisão, da internet ou na escola. Mas suas respostas no questionário mostram que este conhecimento foi insuficiente. Barreiro e Filho (2016), citam em sua pesquisa, que os livros de ciências e biologia não apresentam muitas informações sobre os morcegos, não destacam a importância deles no meio ambiente e não desmistificam informações a respeito deste grupo de animais.

\section{Atividade de Educação Ambiental e análise da segunda aplicação do questionário}

Após a aplicação da atividade de Educação Ambiental, os alunos responderam novamente o questionário, para então ser analisado os conhecimentos adquiridos na atividade (Tabela 2).

Ao perguntar sobre a classificação dos morcegos, somente um aluno $(6,3 \%)$, pertencente a área urbana, respondeu que são vampiros, os demais responderam que o morcego é um mamífero. Durante a atividade de Educação Ambiental foi mostrado um exemplar de ave, um de roedor e de morcego, o qual os alunos puderam analisar e citar as diferenças e semelhanças encontradas nos três animais. Foi debatido entre os estudantes o porquê o morcego é enquadrado na classe dos mamíferos e não na das aves e que eles possuem muitas diferenças, tanto morfológicas quanto comportamentais, em relação aos roedores. As respostas obtidas comprovam que esta atividade de comparação foi eficaz, pois durante a atividade, quando questionados, os alunos logo associaram os morcegos com os mamíferos. 
Tabela 2: Respostas obtidas dos alunos de escola de área urbana e rural, por meio do questionário, após a atividade de Educação Ambiental.

\begin{tabular}{lcrcr}
\hline Perguntas sobre morcegos & Escola de Área Urbana & \% & Escola de Área Rural & $\%$ \\
\hline São cegos & Sim & 12,5 & Sim & 0 \\
& Não & 87,5 & Não & 100 \\
Transmissores de doenças & Sim & 100 & Sim & 94,1 \\
& Não & 0 & Não & 5,9 \\
Função/ importância ecológica & Sim & 87,5 & Sim & 94,1 \\
& Não & 12,5 & Não & 0 \\
Medo & Não respondeu & 0 & Não respondeu & 5,9 \\
& Sim & 25 & Sim & 17,6 \\
& Não & 68,8 & Não & 76,5 \\
& Não sabe & 6,3 & Não sabe & 5,9 \\
\hline
\end{tabular}

Fonte: das autoras.

Durante a atividade, os alunos puderam analisar, por meio de visualização de material zoológico, que a morfologia dos morcegos varia conforme seus hábitos alimentares. Na figura 2 podemos perceber que os alimentos citados pelos alunos, estão corretos em relação aos diversos tipos de hábitos alimentares.

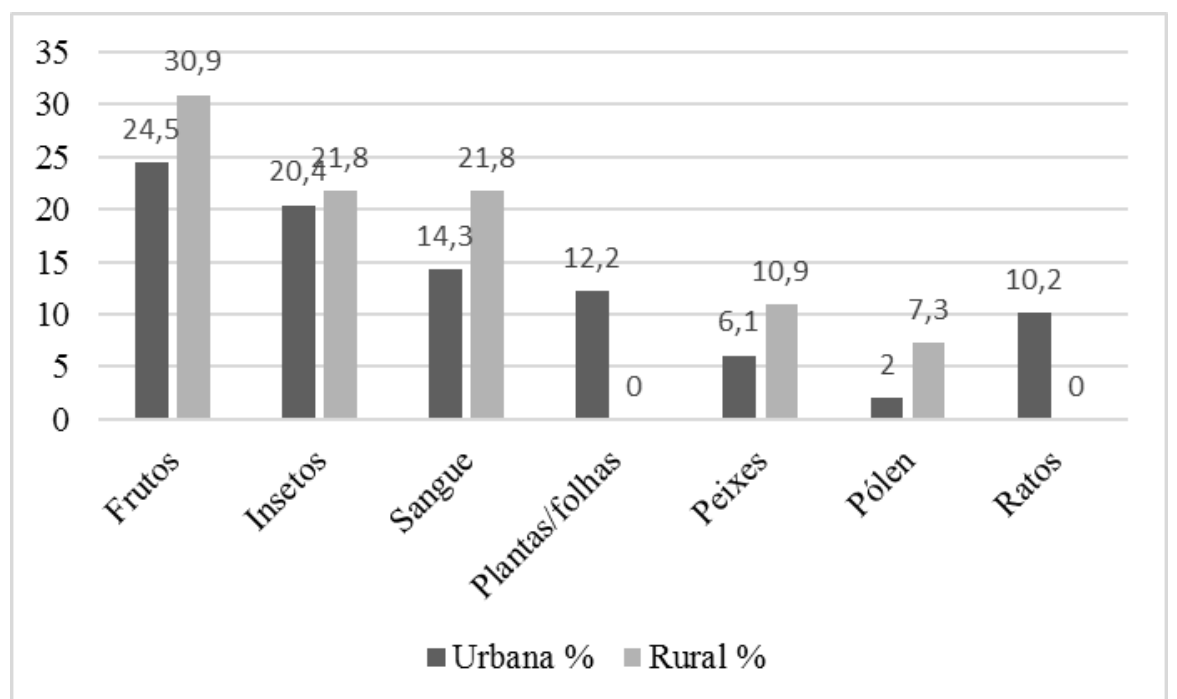

Figura 2: Principais alimentos citados pelos alunos de área rural e urbana, depois da atividade de Educação Ambiental.

Fonte: das autoras.

Ao serem questionados novamente sobre a visão dos morcegos, todos os alunos da área rural responderam que estes animais apresentam visão, sendo que anteriormente grande parte relatou o contrário. Já na área urbana, dois alunos (12,5\%) marcaram que os morcegos são cegos, provavelmente não houve uma compreensão devida ou no momento em que foi enfatizado esta informação, os mesmos estavam dispersos.

Revbea, São Paulo, V. 16, № 2: 316-330, 2021.

Revista brasileira educação ambiental 
Na primeira aplicação do questionário, a maioria dos alunos sabiam que os morcegos poderiam transmitir doenças, mas não sabiam como e quais doenças. Após a atividade de Educação Ambiental, 55\% dos alunos de área rural e $44,4 \%$ de área urbana mencionaram a raiva, e em uma menor porcentagem foram citados fungos e leptospirose, além de ainda $44,4 \%$ dos alunos de área urbana e $15 \%$ de área rural mencionaram que não sabiam o nome da doença. Uma grande porcentagem de alunos não sabe ou não respondeu como os morcegos podem transmitir as doenças. Os alunos que responderam acham que é pela mordida, fezes, urina ou pelo ar (inalação de fungos). Estas respostas são justificadas, pois na atividade realizada não houve muito enfoque em doenças, já que os morcegos apresentam mais benefícios aos seres humanos do que malefícios.

Em relação as funções dos morcegos na natureza, houve um aumento no porcentual de ambas as escolas, se comparado ao questionário aplicado antes da atividade. Na área urbana foi citado como função dos morcegos: "matam insetos" (35,3\%), "espalham sementes" (23,5\%), "várias funções" $(17,6 \%)$ e "polinização" (11,8\%). Mostrando que os alunos de zona urbana, além de compreender a importância dos morcegos, conseguiram entender o conceito "função ecológica". Já os alunos da outra escola compreenderam a importância dos morcegos, citando: "polinização" $(30,4 \%)$, "espalhar sementes" $(26,1 \%)$, "controle de insetos" (13\%), e um aluno $(4,3 \%)$ citou o morcego como "amigo do agricultor".

O medo de alguns alunos de área urbana foi justificado pelo fato de: "os morcegos podem transmitir doenças", "alguns chupam nosso sangue" e "são feios". Os três alunos de área rural que responderam que tem medo de morcegos, justificam falando que eles são assustadores. Já a maioria, que não apresentada medo, diz que os morcegos têm como características: "justos e amorosos", "inofensivos", "fazem parte da natureza", "ele não incomoda" "ataques em seres humanos são raros", "aprendi e sei o que fazer" e "somente três espécies são hematófagas".

\section{Análise de desenhos}

Os alunos, de ambas as escolas realizaram desenhos nas duas etapas de aplicação do questionário.

Os desenhos dos alunos de área rural (Figura 3) mostram que há duas ideias principais sobre os morcegos. Uma que eles estão associados com sangue, coloração de pelos sempre preta e dentes enormes. A outra parte dos alunos desenhou os morcegos vivendo na natureza, em árvores, cavernas, de cabeça para baixo, próximo de insetos, ou então, ajudando na dispersão das sementes. 


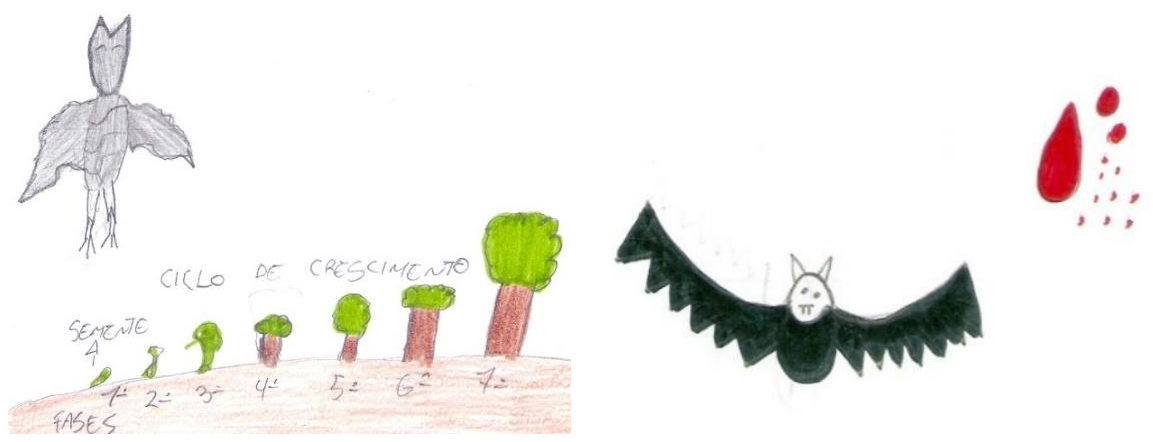

Figura 3: Desenhos elaborados por alunos de área rural, antes da atividade de Educação Ambiental. Fonte: Elaborados pelos alunos.

Muitos alunos de área urbana (Figura 4) associaram os morcegos com a noite, mostrando que eles têm conhecimento de seu hábito noturno, outros desenharam o morcego em harmonia com a natureza, pendurado em árvores, de cabeça para baixo, ou então citaram que "os morcegos são fofos". A outra parte dos alunos desenhou o morcego relacionado com os vampiros e halloween, ou então escreveu que eles são perigosos.

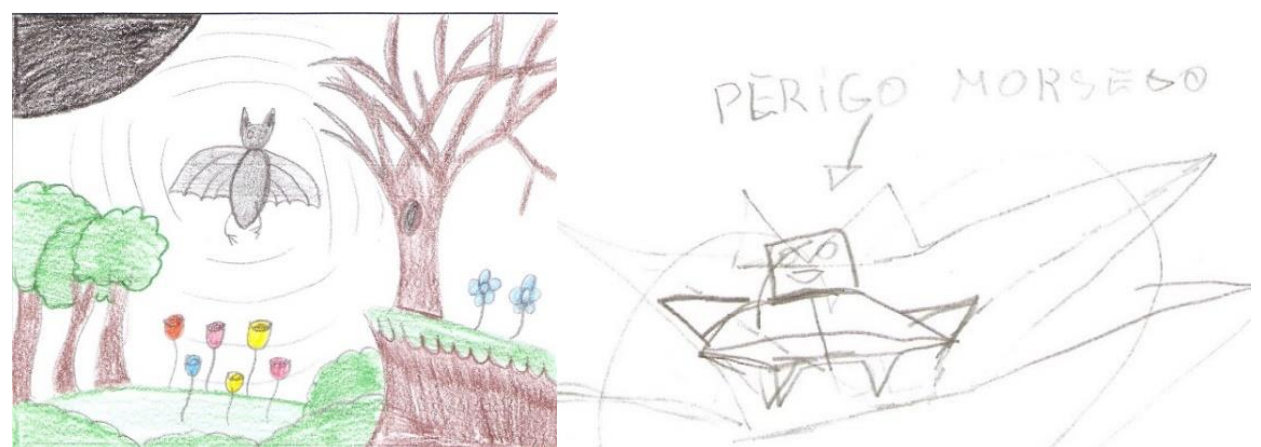

Figura 4: Desenhos elaborados por alunos de área urbana, antes da atividade de Educação Ambiental. Fonte: Elaborados pelos alunos.

Posteriormente a Educação Ambiental, os alunos de área rural demonstraram em seus desenhos (Figura 5) aspectos da morfologia dos morcegos. Alguns desenharam os cinco dedos dos morcegos com os polegares para fora das asas e a folha nasal. Na maioria dos desenhos, o morcego aparecia com aspecto feliz e algumas vezes palavras como "amigo", "viva a natureza" eram destacadas, juntamente com a ligação do morcego com a natureza e a polinização.

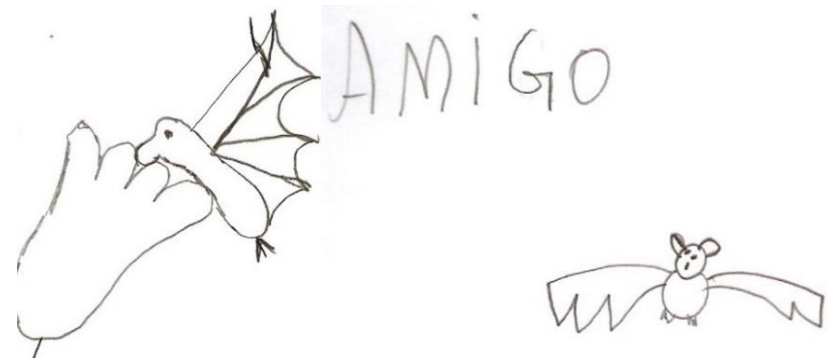

Figura 5: Desenhos elaborados por alunos de área rural, depois da atividade de Educação Ambiental. Fonte: Elaborados pelos alunos.

Revbea, São Paulo, V. 16, № 2: 316-330, 2021.

Revista brasileira educação ambiental 
Os desenhos dos alunos de área urbana (Figura 6), demostraram uma diferença se comparado com os que foram feitos antes da atividade sobre morcegos. Muitos desenharam aspectos relacionados a morfologia, abrigos e hábitos alimentares. Foi citado "morcego é bonzinho", "morcego come insetos" e "eles são como animais de estimação". Somente dois desenhos apresentaram aspectos negativos, um relacionou novamente com vampiro e outro com o halloween. Mostrando que estes mitos e associações permanecem enraizados em algumas pessoas.

Figura 5: Desenhos elaborados por alunos de área urbana, depois da atividade de Educação Ambiental. Fonte: Elaborados pelos alunos.

\section{Considerações finais}

As funções ecológicas dos morcegos são muito importantes, pois são controladores de diversas espécies de invertebrados e vertebrados, são dispersores de sementes e polinizadores de várias plantas. Muitas pessoas, como os alunos, não têm esse conhecimento, pois nunca aprenderam sobre ou não questionaram se os mitos $e$ as crenças são verdadeiros. Por consequência, muitos morcegos são mortos ou deslocados de seus abrigos, podendo ocorrer, em longo prazo, uma extinção de espécies gerando um desequilíbrio ecológico.

Por este motivo a Educação Ambiental é fundamental, não só nas escolas, mas em toda a comunidade. As pessoas precisam conhecer e entender as funções ecológicas, hábitos alimentares e a morfologia dos morcegos, para assim, compreender sua importância na natureza e os benefícios que eles trazem aos seres humanos. $O$ medo e as informações erradas sobre os morcegos reduziram após a atividade de Educação Ambiental, mostrando que a percepção dos alunos foi modificada positivamente. Conclui-se que as atividades de Educação Ambiental são eficientes na quebra de preconceitos e mitos impostos pela sociedade. A falta de informação é algo preocupante, já que em alguns casos pode até ocasionar a morte destes animais. Estes conhecimentos adquiridos provavelmente serão repassados pelos alunos para as pessoas mais próximas, como familiares e amigos, desmistificando crenças antigas e provocando um novo olhar a este grupo animal. 


\section{Agradecimentos}

A direção e professores das escolas por permitirem a aplicação da pesquisa. A Universidade do Vale do Taquari - Univates, tornando possível o desenvolvimento do presente artigo, fazendo parte das exigências para a obtenção da conclusão de curso de Ciências Biológicas Licenciatura.

\section{Referências}

BARREIRO, M. J.; ORTÊNCIO FILHO, H. Análise de livros didáticos sobre o tema "morcegos". Ciência e Educação, Bauru, v. 22, n. 3, 2016.

BERNARD, E. et al. Uma análise de horizontes sobre a conservação de morcegos no Brasil. In: FREITAS, T. R. O. \& VIEIRA, E. M. (Org.). Mamíferos do Brasil: Genética, Sistemática, Ecologia e Conservação. Rio de Janeiro: Sociedade Brasileira de Mastozoologia, 2012.

BREDT, A.; UIEDA, W.; PEDRO, W. A. Plantas e morcegos: na recuperação de áreas degradadas e na paisagem urbana. Brasília (DF): Rede de sementes do cerrado, 2012.

BREDT, A.; SILVA, D.M. (Colab.). Morcegos em áreas urbanas e rurais: manual de manejo e controle. Brasília (DF): 1998.

DRUMMOND, S.M. Morcegos: folclore e mitos. In: PACHECO, S.M.; MARQUES, R.V.; ESBÉRARD, C.E.L. (Org.) Morcegos no Brasil: biologia, sistemática, ecologia e conservação. Porto Alegre: Armazém Digital, 2008, p. 461-469.

KASPER, C. B. et al. Mamíferos do Vale do Taquari, região central do Rio Grande do Sul. Biociências, Porto Alegre, v.15, n.1, p.53-62, 2007.

MANSOLO, A. Educação Ambiental na perspectiva da ecologia integral:

como educar neste mundo em desequilíbrio? Belo Horizonte: Autêntica, 2012.

MARQUES, R. V.; PACHECO, S. M. Morcegos predadores. In: PACHECO, S. M.; MARQUES, R. V.; ESBÉRARD, C. E. L. (Org.) Morcegos no Brasil: biologia, sistemática, ecologia e conservação. Porto Alegre: Armazém Digital, 2008, p. 249-256.

MELLO, M. A. R.; PASSOS, F. C. Frugivoria em morcegos brasileiros. In: PACHECO, S. M.; MARQUES, R. V.; ESBÉRARD, C. E. L. (Org.) Morcegos no Brasil: biologia, sistemática, ecologia e conservação. Porto Alegre: Armazém Digital, 2008, p. 221-232.

NOGUEIRA, M.R. et al. Checklist of Brazilian bats, with comments on original records. Check List, v. 10, p. 808-821, 2014.

NOVAES, R. L. M. Morcegos neotropicais: biologia, ecologia e técnicas de coleta. Rio de Janeiro: Apostila básica. Projeto Pró-Morcegos, 2008. 
PACHECO, S. M. et al. Morcegos de áreas urbanas da Região Sul do Brasil. In: PACHECO, S. M.; MARQUES, R. V.; ESBÉRARD, C. E. L. (Org.) Morcegos no Brasil: biologia, sistemática, ecologia e conservação. Porto Alegre: Armazém Digital, 2008, p. 415-425.

PACHECO, S. M. et al. Morcegos Urbanos: Status do Conhecimento e Plano de Ação para a Conservação no Brasil. Chiroptera Neotropical, São Paulo, v. 16, n. 1, 2010.

PALEARI, L. M. Homens, morcegos e ambiente: uma abordagem ecológica para a educação. In: PACHECO, S. M.; MARQUES, R. V.; ESBÉRARD, C. E. L. (Org.) Morcegos no Brasil: biologia, sistemática, ecologia e conservação. Porto Alegre: Armazém Digital, 2008, p. 187-206.

PASSOS, F. C. et al. Morcegos da Região Sul do Brasil: análise comparativa da riqueza de espécies, novos registros e atualizações nomenclaturais (Mammalia, Chiroptera). Iheringia, Série Zoologia, Porto Alegre, v.100, n.1, 2010.

PREFEITURA MUNICIPAL DE TEUTÔNIA. O município - apresentação, 2019. Disponível em: <http://www.teutonia.rs.gov.br/o-municipio/>. Acesso em: 20 maio 2019.

REIS, N. R. et al. O que é melhor para manter a riqueza de espécies de morcegos (Mammalia, Chiroptera): um fragmento florestal grande ou vários fragmentos de pequeno tamanho? Revista Brasileira de Zoologia, Curitiba, v.20, n.2, 2003.

REIS, N. R. et al. Sobre os Morcegos Brasileiros. In: REIS, N. R. et al (Org.) Morcegos do Brasil. Londrina: Nelio R. dos Reis, 2007, p. 17-25.

REIS, N. R. et al. Morcegos do Brasil: guia de campo. Rio de Janeiro: Technical Books Editora, 2013.

SILVA, F. Mamíferos Silvestres: Rio Grande do Sul. Porto Alegre: Vi;a Sapiens, Fundação Zoobotânica, 2014.

UIEDA, W. História natural: dos morcegos hematófagos no Brasil. In: PACHECO, S. M.; MARQUES, R. V.; ESBERARD, C. E. L. (Org.) Morcegos no Brasil: biologia, sistemática, ecologia e conservação. Porto Alegre: Armazém Digital, 2008, p. 187-206.

VOIGHT, C.C.; KINGSTON, T. Bats in the Anthropocene: Conservation of Bats in a Changing World. [S.I]: Springer, 2016.

ZORTÉA, M.; AGUIAR, L. M. S. Conservação dos morcegos brasileiros. In: PACHECO, S. M.; MARQUES, R. V.; ESBÉRARD, C. E. L. (Org.) Morcegos no Brasil: biologia, sistemática, ecologia e conservação. Porto Alegre: Armazém Digital, 2008, p. 385-392. 